\title{
Tourism constraints on transgender individuals in Mexico
}

\section{Cite this paper as:}

Monterrubio, C., Mendoza-Ontiveros, M. M., Rodríguez Madera, S. L. \& Pérez, J. (2020). Tourism constraints on transgender individuals in Mexico. Tourism and Hospitality Research. https://doi.org/10.1177/1467358420948564

\begin{abstract}
Transgender or trans people are deeply affected by social stigma in a wide range of forms and contexts including family, school, neighbourhood, work and clinical settings. Studies have rarely focused on how stigmatisation affects trans individuals' experiences of travel and tourism. This research sought to critically explore the constraints that prevent trans people from engaging in tourism in Mexico. We conducted in-depth interviews with 15 trans participants. Experiences related to intrapersonal, interpersonal and structural constraints on tourism were explored during interviews. The findings include that trans men and women do not experience tourism constraints equally, and interpersonal constraints are closely related to social stigma that in turn influence these individuals' fear of being discriminated against, abused or killed while travelling or engaging in leisure activities. The results are discussed in light of leisure and tourism constraints theory. Managerial implications include ways that the tourism industry can contribute to reducing constraints for trans travellers.
\end{abstract}

\section{Introduction}

Due to social stigma, transgender or trans people are frequently placed in vulnerable situations in their everyday lives, resulting in a high risk of health problems, under- and unemployment, poverty and - the focus of this article - reduced access to leisure opportunities and tourism (Bradford et al. 2013; Brennan et al. 2012; Padilla et al. 2016). Trans individuals are those for whom sex (i.e. physical characteristics) and gender (i.e. self and social identity) are not always congruent (Blight 2000). In the present research, the term 'trans people' refers to individuals whose gender identity is framed within the gender binary approach. Thus, transgender here does not allude to gender non- 
conforming or non-binary people. Trans individuals may be male-to-female (i.e. trans women) or female-to-male (i.e. trans men).

Global studies on trans people have revealed a complicated panorama regarding citizen rights, health and life expectancy (Bockting et al. 2013; Bradford et al. 2013; Padilla et al. 2016; Reisner et al. 2014; Rodríguez-Madera et al. 2017; Socías et al. 2014). In general, this population segment experiences significant personal, social and health disadvantages in areas such as income levels, job opportunities, access to health-related services and safe housing (Rodríguez Madera et al. 2015). In addition, the high levels of violence and microaggressions to which trans individuals are frequently exposed are a serious threat to their health and wellbeing (Chang and Chung 2015; Rodríguez-Madera et al. 2017; Stotzer 2009; Wirtz et al. 2020).

The existing evidence suggests that trans people's experiences are deeply affected by social stigma and transphobia in a wide range of forms. These include violence (e.g. interpersonal and institutional) and discrimination in multiple contexts including family, school, neighbourhood, work and clinical settings (Bradford et al. 2013; Grant et al. 2011; Sears and Mallory 2011). Thus, trans individuals commonly use high mobility as a strategy to find spaces that are accepting of them in terms of lifestyle, work or adequate healthcare (Howe et al. 2008; Monterrubio et al. 2020).

Marshall et al.'s (2019) recent study of how trans people have been represented in research and the specific areas that have been investigated provides valuable information about the remaining gaps. According to the cited authors, topics that have received the most attention include therapeutics and surgeries; gender and expression; physical, mental and sexual health; discrimination and marginalisation; human immunodeficiency virus (HIV) and sexually transmitted infections (STIs); health-related services; social support; relationships; families; and resilience. The areas that have been less researched are linked to the social determinants of health such as ethnicity, culture, housing, income, employment and space and place (Marshall et al. 2019). Trans individuals' travel and tourism experiences have also been largely neglected, or they have been included under the umbrella of lesbian, gay, bisexual and transgender (LGBT) tourism. However, the latter approach has meant that researchers mistakenly assume trans people's tourism constraints and experiences are the same as those of other LGBT community members. In addition, specific sociocultural contexts such as Mexico, offer environments characterised 
by discrimination, hostility, harassment and violence against trans individuals, yet little is known about how they experience tourism in these settings.

Investigating leisure activities and tourism necessarily implies understanding their intersection with key determinants, including social stigma - one of the constraints that can most restrict trans people's opportunities to engage in leisure pursuits and tourism (Monterrubio et al. 2020; Olson and Reddy-Best 2019). Recreation constraints are not equally distributed across society, with socio-demographic characteristics playing a significant role in constraints' prevalence and extent (Shores et al. 2007). Therefore, a leisure constraints framework has been used to understand tourists' experiences and behaviours among specific social subgroups such as women (Fendt and Wilson 2012; Henderson and Bialeschki 1993), senior citizens (Fleischer and Pizam 2002; Gao and Kerstetter 2016; Huber et al. 2018), disabled individuals (Smith 1987), lesbians and gay men (Lee et al. 2012; Weeden et al. 2016). In other words, researchers have investigated leisure and tourism constraints related to gender, age, disability and sexual orientation. Nevertheless, according to Wilson and Little (2005), 'constraints remain only a nascent area of study within the field of tourism and thus our current knowledge remains superficial at best' (p. 156). How tourism constraints are perceived and experienced by gender dissidents (i.e. those who are beyond conventional gender norms such as trans individuals) is still largely unknown, so studies are needed to develop a deeper understanding of tourism constraints on trans people.

The present research sought to critically explore the intrapersonal, interpersonal and structural constraints that trans individuals experience when participating in tourism. This study had two objectives: 1) to contribute to the understanding of how tourism constraints are perceived by trans individuals and 2) to demonstrate the value of applying leisure and tourism constraints theory to trans tourism research.

\section{Theoretical framework}

\section{Social stigma theory and leisure constraints theory}

This study applied two approaches: social stigma theory and leisure constraints theory. The former refers to disapproval of or discrimination against individuals based on perceived social characteristics that distinguish them from other members of society (Kleinman and Hall-Clifford 2009). More specifically, stigmatisation is the social process 
of labelling, stereotyping and rejecting human differences as a form of social control (Link and Phelan 2001; Phelan et al. 2008). Similarly to how constraints can be addressed from an intrapersonal, interpersonal and structural perspective, stigmatisation can also be conceptualised as a multilevel process (White Hughto et al. 2015).

Stigma manifests itself at the structural level through societal norms, environmental conditions and institutional laws and practices that limit stigmatised people's resources, opportunities and wellbeing (Hatzenbuehler et al. 2010). An example of this type of social stigma experienced by the trans population is the absence of health insurance coverage of gender-affirming medical interventions. Stigma at the interpersonal level is related to societal norms and beliefs that can often have negative consequences for interactions with others (White Hughto et al. 2015). An example is the risk of physical and psychological violence in social and intimate interactions due to individuals' gender identity and expression. Finally, stigma at the intrapersonal level refers to psychological processes affected by stigmatisation experiences shaping individuals' basic orientation to themselves, others and their external circumstances (White Hughto et al. 2015). For instance, certain leisure activities generate shame and avoidance due to internalised stereotypes and negative experiences with other people (Rodríguez Madera et al. 2019).

Leisure constraints theory focuses on the relationships between constraints and leisure preferences and involvement (Godbey et al. 2010). Most research on constraints that limit participation in these activities has been conducted during the last three decades (Crawford and Godbey 1987; Fendt and Wilson 2012; Huber et al. 2018; Hudson and Gilbert 2000; Jackson et al. 1993). Constraints were initially conceived of as barriers rather than restrictions. Crawford and Godbey (1987) state that 'a barrier is any factor which intervenes between the preference for an activity and participation in it' (p. 120). Although constraints are often labelled as 'perceived' phenomena (Gilbert and Hudson 2000), constraints in leisure and tourism influence individuals' recreational and travel choices, activities and behaviours. These barriers are dynamic in nature, and they are often based on issues such as age, race and gender (Gao and Kerstetter 2016).

Crawford and Godbey (1987) developed a hierarchical leisure constraints model in which the constraints that affect the relationship between leisure preferences and participation are manifested on three levels: intrapersonal, interpersonal and structural. Intrapersonal constraints involve individual psychological states and attributes that interact with 
leisure preferences, which include, among others, stress, depression, anxiety, religiosity, prior socialisation, reference group attitudes and subjective evaluations. These constraints are relatively unstable or changeable by nature and thus can be modified over time. They also interact with leisure preferences directly rather than intervening between preferences and participation. Within tourism, intrapersonal constraints can take the form of safety and health concerns and culture shock (Gao and Kerstetter 2006)

Interpersonal constraints are the result of interpersonal interactions or the relationships between individuals' characteristics, so these constraints arise out of spousal interactions, family relationships and interpersonal relations, in general, and are often applicable to companionate leisure activities. Individuals may thus experience interpersonal leisure constraints if they are unable to locate a suitable partner with whom to participate in particular activities. These constraints can interact with both preferences and participation in leisure pastimes (Kattiyapornpong and Miller 2009). In tourism contexts, a lack of travel partners has been reported as a significant interpersonal constraint (Gao and Kerstetter 2006; Gilbert and Hudson 2000).

Structural constraints, in turn, refer to the broader context outside individuals (Huber et al. 2018), in which these constraints are intervening factors between leisure preferences and participation. Some examples are financial resources, availability of time, access, season, climate and group attitudes towards specific activities (Crawford and Godbey 1987). Researchers have suggested that this type of constraint tends to be unexpectedly complex as it often encompasses more than one construct (Nyaupane et al. 2004). A lack of money and time has been found to function as structural constraints in tourism contexts (Gilbert and Hudson 2000).

Intrapersonal, interpersonal and structural constraints can overlap not only because all three can be experienced simultaneously but also because, as confirmed by the present study, some constraints are associated with the same social entities. Although more than one type of barrier may be present at any given moment, Godbey et al. (2010) state that, in this hierarchical model, each form of constraint needs to be navigated sequentially for participation to take place. Hudson and Gilbert (2000) also affirm that '[e]ach level of constraint must be overcome in order for an individual to face the subsequent level of constraint' (p. 72). As a result, 'individuals who are most affected by intrapersonal difficulties would be less likely to want to participate in a given leisure activity and thus 
would not reach higher order constraints (interpersonal and structural)' (Gilbert and Hudson 2000, p. 911).

Constraints can also be classified as internal or external. While internal constraints often include personal skills, abilities, knowledge and health problems, external barriers typically comprise a lack of time, financial cost, a lack of facilities and transportation problems (Gilbert and Hudson 2000). Sociodemographic characteristics may become additional relevant constraints. Empirical research has revealed that, in particular, age, gender, income, life cycle, level of education, health conditions and disabilities are likely to be significant constraints on leisure and tourism activities (Alegre et al. 2010; Fleischer and Pizam 2002; Kattiyapornpong and Miller 2009; Nyaupane and Andereck 2008; Pennington-Gray and Kerstetter 2002; Son et al. 2008). Given the above findings, examining the intersections between social stigma and leisure and tourism opportunities could make an important contribution to trans research by providing evidence of the barriers trans people must overcome to ensure their wellbeing.

\section{Gender constraints in leisure and tourism}

The vast majority of studies on constraints in leisure and tourism have focused on cisgender individuals' perspective, namely, the view point of those who maintain a gender identity and expression corresponding to the biological sex with which they were born (Aultman 2014). Trans people's experience of these barriers is, therefore, a gap in the existing theoretical understanding of tourism. Trans people may be constrained not only by issues faced by cisgender travellers, such as a lack of time and money, but also by gender-related issues. Gender is a particularly significant determinant of leisure and tourism participation.

More specifically, researchers have demonstrated that cisgender women experience greater constraints due to their gender. Women must overcome more barriers to leisure participation than their male counterparts do. Women's constraints often include a lack of time, fear of violence, a lack of self-confidence, minority status and responsibilities in the domestic spheres of children, family and household (Arnold and Shinew 1998; Fendt and Wilson 2012; Gilligan 1982; Wilson and Little 2005). Research has also produced evidence that a fear of crime and lack of a partner or compatible travel companions are constraints more frequently found among women versus men (Fendt and Wilson 2012; 
Henderson and Bialeschki 1993). Due to gender-related issues, these barriers are difficult for women to negotiate (Shores et al. 2007).

Within tourism research, cisgender women's constraints have also attracted academic attention. For example, Wilson and Little's (2005) study of female solo travellers found that women experience four types of constraints: sociocultural contexts, travellers' personal beliefs and perceptions, practical challenges and spatial restrictions. Similarly, Gao and Kerstetter (2016) used intersectionality as a guiding theoretical framework to examine travel for pleasure among older Chinese females. Their trips may be constrained by intrapersonal (i.e. a limited knowledge of tourism, health and safety concerns and culture shock), interpersonal (i.e. a lack of travel partners) and structural (i.e. low quality service facilities, limited availability of information, tour guides' negative reputation and few employer-paid holidays) constraints. Despite these barriers, women's participation in leisure and tourism is increasing as they find ways to negotiate solutions (Fendt and Wilson 2012).

Overall, the field of travel constraints has progressed conceptually and theoretically (Gilbert and Hudson 2000), but further empirical research is needed to understand how leisure and travel constraints are experienced by specific social subgroups and minorities whose access to leisure and tourism activities can be compromised. The interrelationships between motivation, constraint and negotiation also need further empirical inquiry (Fendt and Wilson 2012). In addition, studying the particular constraints faced by trans people is important to identifying strategies that facilitate their inclusion in tourism.

\section{The study}

\section{Context}

The present study was carried out in Mexico. Experts estimate that 0.3 to $0.5 \%$ of Mexico's population are individuals who identify themselves as trans (i.e. between 360,000 and 600,000 trans people) (Notimex 2019). Despite the progress made towards recognising the LGBT population's rights in Mexico, discrimination and violence against this group appears to have increased in recent years. The full magnitude of this hostility is unknown due to the country's lack of reliable data. 
The Survey on Discrimination on the Grounds of Sexual Orientation and Gender Identity 2018 (Conapred and Comisión Nacional de Derechos Humanos [CNDH] 2019) confirmed that Mexico comprises an environment of extensive discrimination, hostility, harassment and violence against people who embody gender dissidence or non-normative sexual orientations. The cited study revealed that a generalised hostility is present in all areas of socialisation, which includes practices such as family rejection and school bullies, mockery and humiliation in communities and discrimination at work and in public spaces and services (see Table 1). Discrimination against people with non-normative gender identities is also evident in the impediments to using public restrooms matching their gender identity (51\% of trans individuals), invalidations of their official identification (34.4\%) and prohibitions against entering cinemas, restaurant or bars (28.3\%).

Table 1. Discriminatory practices against gender dissidents in Mexico (\%)

\begin{tabular}{|l|c|c|c|}
\hline \multicolumn{1}{|c|}{ Discrimination due to gender identity } & $\begin{array}{c}\text { Trans } \\
\text { men }\end{array}$ & $\begin{array}{c}\text { Trans } \\
\text { women }\end{array}$ & $\begin{array}{c}\text { Gender } \\
\text { nonconforming }\end{array}$ \\
\hline Perceived discrimination & 74.8 & 74.4 & 80.2 \\
\hline Denial of rights & 40.9 & 53.3 & 36.3 \\
\hline Perceived uncomfortable stares & 76.5 & 70.7 & 69.7 \\
\hline $\begin{array}{l}\text { Negative comments, behaviours and attitudes in } \\
\text { workplaces }\end{array}$ & 42.3 & 43.6 & 41.0 \\
\hline $\begin{array}{l}\text { Discrimination in } \\
\text { medical care }\end{array}$ & 24.0 & 24.5 & 18.8 \\
\hline Negative experiences with police & 19.8 & 35.4 & 29.8 \\
\hline
\end{tabular}

Source: Conapred and CNDH (2019)

According to Brito (2019), trans women or trans people with a female expression are mostly dedicated to styling and sex work in Mexico, and they are the most at risk of being killed. Compared with trans men, trans women tend to experience more socially disapproval in macho societies. Women who renounce being the 'weaker sex' and become a man are more acceptable than trans women who have renounced masculine hegemonic power and demeaned themselves by accepting a lower female status (Meseguer 2017). The predominant social context of discrimination and rejection that surrounds trans women, as well as the difficulty of going unnoticed, puts them at greater risk of being killed and subjected to aggression. In the 2013-2018 period, 261 trans women were murdered, which was 55\% of the total homicides among Mexico's LGBT population. The bodies of murdered trans women are often found on public roads or in vacant lots, with wounds caused by guns and sharp knives. 
Little research has been done on trans people in Mexico, and studies have mostly focused on the issue of HIV and STIs (Vera Morales 2019). The problem of violence against trans individuals and, more specifically, trans women has drawn international attention since Mexico ranks second worldwide in homicide rates again this population segment (i.e. 56 murdered every year). These data are generated by Transgender Europe's (2019) Trans Murder Monitoring project, which is a systematic collection, monitoring and analysis of data on reported killings of trans people around the world. Given the particular features that Mexico has, namely, discrimination and violence rates against trans individuals, this country comprises the ideal context in which to explore the constraints that prevent trans individuals from engaging in tourism and other recreational activities.

\section{Methods}

We recruited participants in the State of Mexico as this is one of the regions with the highest level of trans murders (Brito 2019). The inclusion criterion was individuals who self-identify as trans people. Due to fears of social disapproval, discrimination, verbal harassment and violence, trans individuals cannot publicly disclose their transgender identity, so they are not easily identifiable to others (Maguen et al. 2007). Statistics regarding the number of trans individuals is nearly impossible to find (Dutton et al. 2008), but research and surveys suggest that recruiting trans men for studies is harder than enlisting trans women (Dutton et al. 2008; Fundación Huésped n.d.), which has resulted in a gap in knowledge about trans men. A special effort was made in the present study to contact as many potential participants as possible, and repeated interview requests were conveyed in order to recruit the same number of trans women and trans men. However, the latter were more difficult to identify, contact and invite to participate. According to those interviewed, the smaller number of trans men participants was due to the fear some have of being identified publicly as a trans person.

Fifteen (number [n]=15) trans individuals were interviewed in 2019: 11 trans women and 4 trans men. Their ages ranged from 22 to 51 years old. Most of them self-identified as heterosexual. Low educational levels were verified since, out of 15 participants, only 1 had a university degree, 2 were studying at university at the time of the study and 12 had only completed high school or middle school. The participants reported various nonprofessional occupations, with 5 trans women working as hairstylists and the same number being involved in sex work. The vast majority $(n=14)$ were single, and without 
children. Four trans women and all the trans men $(n=4)$ had changed their identification documents. The multiple body modifications reported included hormone use $(n=14)$, silicone injections for breasts and/or buttocks augmentation $(n=5)$, vaginoplasty $(n=1)$ and a mastectomy and hysterectomy $(\mathrm{n}=1)$. Although this study was exploratory in nature, the different sociodemographic data gathered, as well as the variety of identities and body transformations, facilitated not only the documentation of different experiences but also an exploration of how tourism constraints are shaped by trans people's specific characteristics.

An interview guide was developed based on the existing literature. The guide contained questions regarding sociodemographic information such as age, education and occupation; gender identity; interpersonal experiences in everyday life; and travel and tourism issues such as reasons for travel, destination choice and avoidance and travel experiences. All interviews were audio recorded, and they lasted one hour on average. The participants were recruited through snowball sampling, and, in the case of trans men, an invitation to participate was made through trans men Facebook groups based in Mexico. All interviews were held in person, and most took place in public areas such as cafés and restaurants.

To expediate the analysis, each interview was discussed in general terms immediately after its completion. Next, the interviews were analysed in detail by each researcher, who wrote down a series of impressions. These notes were then collated and merged with the rest of the research team members' impressions. To serve the present research's particular purpose, leisure constraints theory's assumptions were used to scrutinise interviews. The interviews were processed individually and subjected to thematic analysis focused on constraints. These were first identified and then classified into intrapersonal, interpersonal and structural travel constraints, as postulated by the theoretical framework selected.

According to Killion and Fisher (2018), researchers' positionality can influence their data collection and analysis, so constant reflexive practices are needed for researchers to be fully conscious of how they are situated within the research setting. In this case, 4 researchers self-identify as cisgender, while 2 of them are part of the LGBT community. The latter were responsible for conducting the interviews as being part of this community was a valuable component in achieving rapport with the participants. To avoid bias, the 
remaining researchers continuously reflected on the possible impacts their cisgender condition could have on the research process.

Based on Vincent's (2018) suggestion of categories to consider when working with trans individuals, the current research team gained familiarity with the trans population both abroad and in Mexico through the existing literature, conferences and Facebook pages. This process allowed the researchers to become familiarised with, and extremely cautious about, the use of suitable language when conducting interviews. Overall, the researchers felt a moral imperative to undertake this study to contribute to increasing trans populations' visibility and reducing discrimination and social inequality.

\section{Findings}

Travel motivations and constraints are interrelated. According to Božić et al. (2017), understanding not only what motivates but also what hinders individuals from travelling has important practical implications for the tourism industry as both aspects help experts analyse and predict tourists' decisions and consumption behaviours more accurately. Thus, a brief overview of travel motivations was conducted to understand constraints on trans tourism.

Within tourism, trans people's motivations have been mistakenly reported under the umbrella of LGBT tourism. Gender identity issues need to be distinguished from sexual orientation (Zimman 2009). Dutton et al. (2008) argue that 'LGB issues are most often concerned with one person's sexual relationship to another individual, while transgender issues focus on one individual's gender identity' (p. 331). Nonetheless, most research on LGBT tourism has overlooked the 'T' and assumed that trans people's tourism experiences and constraints are the same as those of gay and lesbian community members. Trans individuals' travel motivations and experiences have, therefore, been misrepresented and remain largely unknown - due to the predominant academic interest in gay and lesbian issues. Gay tourists' motivations and constraints should not be considered analogous to those of trans tourists.

The present study's results reveal that trans people's motivational factors are similar to those of cisgender tourists. Push factors such as rest, relaxation, socialisation and family bonding, on the one hand, and the pull factors of culture, nature, food and weather, on the other, were described as significant by the participants. While push motivations refer to 
individuals' internal motivational factors, pull motivations refer to characteristics specific to destinations (Snepenger et al. 2006). Lorena, who was 24 years old and who had travelled mainly with friends, asserted, 'I travel to have fun, to have a good time, to relax and to spend time with my friends.' Miranda, who reported perceived sexual harassment, said, 'I like nature, [and] to experience new places, cultures and indigenous communities.' Unlike sexuality-oriented tourism (Hughes 2002; Monterrubio 2009; Pritchard et al. 2000), gender identity confirmation was not found to be a significant intrinsic motivational factor for trans travel.

Intrapersonal, interpersonal and structural constraints coexist in trans tourism. They can even intersect, especially when personal characteristics, social relationships and structural components interact. The current research's analysis revealed that the three types of constraints, unlike barriers experienced by other social subgroups, are associated primarily with trans-based stigmatisation practices such as discrimination, mistreatment and violence manifested at an interpersonal level. The results also reveal that, at least for the trans people interviewed, intrapersonal constraints are the most significant. While the constraints described apply to both trans women and men, the degree and ways in which these barriers are experienced varies by gender. As discussed further below, this variation largely depends on passing as female or male and general gender issues.

\section{Intrapersonal}

Fear of social stigma manifestations particularly at the interpersonal level (i.e. discrimination, violence and murder) proved to be the most dominant intrapersonal constraint on travel. Both trans women and men expressed a dread of being discriminated against, mistreated, attacked and even murdered while travelling. They are aware that trans people are quite vulnerable in social settings, especially when away from home. Lorena, a trans woman who started sex work at the age of 18, said, 'I don't travel because I'm afraid of being discriminated against... I'm afraid of being murdered.' While participants appear to have normalised microaggressions, such as being misgendered and insulted and people's whispering and staring, the interviewees are afraid of being the target of physical violence. Mainly in the case of trans women, they are also fearful of becoming victims of sexual harassment, physical violence and murder. They tend to feel anxious about not being able to pass unnoticed as a trans person. Rody suggested that trans women are more identifiable and vulnerable than trans men are when travelling. 
When asked about his perceived safety on trips, he asserted, 'I feel insecure in all the public places... If a man realises that I urinate sitting or that I do not have a penis, my life could be at risk.'

Trans people are also prone to experiencing anxiety about their gender expression not matching their official identification in travel situations, which can trigger intrapersonal stigma. This danger applies particularly to trans individuals who have not updated their official documents. Some interviewees have experienced uneasiness about being questioned regarding their gender when showing their identification upon, for instance, boarding a plane or bus. Various participants are uncomfortable with being questioned about their identification and identity, which they feel is annoying or even a form of mistreatment. Given how the three types of constraints can intersect, identification requirements can become a structural constraint that some trans people encounter.

Gender transition is a process that goes from the initial private claiming of trans identity to publicly sharing the new identity after transitioning (Zimman 2009). Thus, trans individuals' travel experiences and constraints must include experiences before and after transition. Few participants in the present study expressed having good memories of travelling with the gender assigned at birth, but others reported that travelling before their transition made them feel uncomfortable due to playing a role with which they did not identify. Abigail, who has felt discriminated against and sexually harassed by men, said, 'travelling as a boy made me feel bad. I did not know how to wear clothes as a boy. I did not feel comfortable. It was not me.' In some cases, this discomfort deterred them from travelling or from getting involved in specific leisure activities while travelling. Miranda has travelled abroad for professional sport competitions and has been rejected by her family members. She shared, 'when I travel, I avoid certain type of bars where I do not feel safe. Even if I wanted to drink a beer, I would avoid going to bars... Drunk men become crazy, so I would not risk my life in places I don't know.'

This study revealed that constraints are not only associated with travelling but also with trans people's activities while on trips. In other words, once in their destination, trans individuals may opt not to do certain things because they feel constrained by social stigma. One such constraint is their anxiety about using toilet facilities. Most participants have at some point felt nervous about being asked to use toilets not matching their gender identity, which also applies to travelling. Amanda said: 
I tried to access the women's toilets, but they said, 'the men's toilets are over there.' I told them I could not enter the men's toilet dressed as a woman. In the end, they did not allow me to enter the women's [toilets].

Although this study's findings cannot be generalised to the entire trans population without due caution, the results indicate that this constraint is more significant for those individuals who are unable to pass easily as their post-transition gender. As discussed below, the issue of gendered toilets is also a structural constraint for trans people in tourism and recreational activities.

Recreational activities in the destination may similarly be restrained by concerns about showing their unmodified body to others. This anxiety was mostly reported by trans men who have not had a mastectomy. Men tend to experience uneasiness in spaces such as beaches or pools, where they should take off their top but they feel afraid to show their chest. Ryan, who never felt himself in dresses, asserted:

Wearing a swimsuit is problematic. Most men who go to the beach only go around with their shorts and bare chests. For us it is more complicated. There are places like swimming pools or water parks and even hotels that do not let you in with a shirt. Then suddenly that makes you feel a little bad.

For trans men, the use of binders is suspicious, so going with their top half naked places them in vulnerable situations. This constraint inhibits trans men from getting involved in recreational activities or fully enjoying certain leisure facilities.

\section{Interpersonal}

Trans tourism is characterised by collective travel, although this seems to apply more to trans women than to trans men. The interviewees' responses suggest that trans people tend to travel with family or friends. Very few trans women travel alone, and they do so for work. Unlike trans men, none of them reported travelling solo for recreation. Fadel, who feels self-confident going to the beach due to a mastectomy, commented, 'sometimes I travel with my family or friends, and sometimes I travel alone. I have no problem traveling alone. In fact I enjoy it.' These results indicate that, unlike trans women, trans men tend to engage more in solo recreational travel because gender passing in trans males is often good enough for them to go unnoticed, making them less fearful and causing them to perceive a lower risk of harassment. 
The study's results show that specific manifestations of stigma including microaggressions, such as whispering and being misgendered, have been normalised by trans people. Thus, microaggressions are not necessarily perceived as violence or mistreatment, which is common in experiences of internalised stigma. However, some participants expressed concerns about travelling with family members as these members may feel embarrassed, offended or uncomfortable if other people question the trans individual's gender identity. Joanne, a 22-year-old trans woman who perceives her gender passing as insufficient, said, 'when I go out with my parents, I try to be more cautious, more discrete. I even try to hide. People's comments would affect my parents.' Participation in travel and leisure activities with family may, therefore, be deterred by trans travellers' anxiety about making their family feel uncomfortable.

Trans people can also experience family disapproval and rejection (Molina et al. 2015). Many participants initially had difficulty overcoming family members' lack of understanding and disapproval. Although some trans individuals interviewed have gained their family's acceptance and support, cases were reported of the absence of relatives' acceptance inhibiting going on trips to visit them. In John's case, he decided not to travel to attend a wedding because his extended family disapproves of his gender identity.

The great majority of the participants did not have a partner at the time of their interview. Due to stigmatisation, having a stable partner is uncommon, especially for trans women. The trans men interviewed appeared not to encounter this consequence of stigmatisation so frequently. Their ability to pass as male is enough to make a public relationship with a woman unproblematic. Based on the evidence gathered, trans men are more likely to pass unnoticed compared with trans women, so these men may feel more confident about having overt relationships with women. In contrast, many trans women do not go unnoticed, which means appearing in public with their male partners can be regarded by others as openly engaging in homosexuality. In addition, unlike trans men, some trans women reported playing the role of an illicit lover as many are forced by social norms to keep their romantic relationships secret. In these cases, travelling with their partner remains an unfulfilled aspiration.

Destination experiences are further constrained by interpersonal interactions. Interviewees reported modifying their behaviours depending on whether they travel with 
family or friends. When travelling with friends, they tend to engage in more festive behaviours including going to pubs and discos, drinking more alcohol and, mostly for trans women, meeting new people for romance or sex. Trans men expressed more restraint and caution regarding these issues, which has much to do with learnt gender roles. Trans men are raised as females, so they are taught to be more introverted, socialise in more intimate groups and participate in independent activities and more exclusive, dyadic relationships than the kinds of interactions boys are allowed (Adler et al. 1992). For trans people, travelling with others can either constrain or encourage specific travel and leisure activities.

\section{Structural}

From a sociological perspective, structural constraints include the various political, economic, social and cultural factors that constrict individuals' decision-making ability (Editorial 2016). These constraints are related to interpersonal barriers and affect intrapersonal constraints. Based on the present interviews, trans people feel primarily constrained by transphobic environments. The participants are fully aware of the sociocultural conditions in which trans individuals live in Mexico, namely, discrimination, transphobia and homophobia. Although homophobia refers to prejudice against homosexuality and transphobia against transgender individuals, trans people tend to be victim of both because trans individuals are strongly and frequently associated with homosexuality (Molina et al. 2015).

Most participants clearly stated they would not visit a destination with a transphobic reputation. Discrimination, cisgenderism and transphobia are thus the most relevant structural constraints for trans tourism. Dana, who has been the victim of violent attacks due to her gender identity, stated, 'I would not go to homophobic and transphobic places, nor would I go to macho places. They don't want trans women.' This constraint comprises a significant finding as previous research has not clarified how prejudice towards gender dissidence restrains travel and leisure activities.

Gendered facilities similarly represent an important barrier to trans people's leisure and tourism experiences. The issue of toilets can become both an intrapersonal and structural constraint. While the intrapersonal dimension reflects the anxiety trans individuals experience when having to use toilet facilities, the structural barrier is present when 
gendered toilets are seen as a product of binary social norms imposed on trans people. This finding confirms that different types of constraints based on one specific issue (i.e. toilets) can overlap. According to Olson and Reddy-Best (2019), trans individuals may opt for avoiding places - and public toilets in particular - that force them to make a binary decision.

Both trans women and men in the current study reported having negative experiences of not being allowed to use female and male toilets, respectively. John, who has not changed his body, told the following story:

I was on a trip. My sister and I entered a shopping centre, but they did not let me enter the men's room. They asked me to go to the women's room, even though I was dressed like a man. I was literally taken out of the women's toilet by the women, so I couldn't get into either the women's restroom or the men's restroom.

Based on the participants' experiences, their ability to use the toilet facilities that correspond to their gender identity largely depends on being able to pass as a female or male. Thus, gendered toilets are extremely significant components of experiences in public spaces. Some trans people, especially those with insufficient levels of gender passing, may even avoid using toilets in certain places.

One final structural constraint is related to income since, in Mexico, trans individuals tend to be unemployed, making their income precarious (Molina et al. 2015). The trans men participating in this study generally reported higher incomes compared with the trans women interviewed, but, overall, limited income is another relevant structural barrier to travel. Due to their nonprofessional occupations, most participants $(n=13)$ reported unstable wages, with an overall average monthly income of 300 United States dollars $(6,000$ Mexican pesos). Many of the interviewees would like to travel more often and abroad, yet they are restrained by precarious incomes.

\section{Discussion}

This study's results confirm that the trans population, based on the people interviewed, experience multiple challenges due to social stigma. This stigma is rooted in cultural ideals that cause gender identities that do not conform with assigned gender at birth to be degraded or even pathologised (Lennon and Mistler 2014). The present research showed that trans people's access to education, labour, health and a life free of violence is 
limited compared with cisgender individuals, thereby corroborating previous studies (Chang and Chung 2015; Rodríguez Madera et al. 2015; Socías et al. 2014). The plethora of stigma-related experiences (e.g. disapproval, discrimination against and negative attitudes towards many trans people) put these individuals in vulnerable situations in which verbal and physical violence - including the possibility of being killed - are part of their everyday lives. The current research revealed that transphobia, in its multiple manifestations, is also experienced in travel, tourism and leisure contexts.

For many years, the alleged LGBT market's economic value has been emphasised. LGBT travellers are believed to seek specific travel experiences and to be a quite lucrative market for the travel, tourism and hospitality industries (Guaracino and Salvato, 2017). Trans people's travel experiences have been mistakenly included under the umbrella of gay tourism. While gay, lesbian, bisexual and trans individuals constitute social minority groups, LGB people's experiences are mainly shaped by sexual orientation while trans experiences are significantly defined by gender issues.

The present study's results highlight that travel and tourism do not have the same significance for LGB and trans individuals. The literature on gay and lesbian tourism reveals that LGB tourists' motivations are strongly associated with sexual identity, socialisation with other gay and lesbian people and escapes from heterosexism (Hughes 1997; Monterrubio 2009; Pritchard et al. 2000; Waitt and Markwell 2006). The current findings include that trans tourism motivations are not primarily related to sexual or gender identity. Trans individuals' motivations are instead quite similar to those of cisgender tourists in terms of both push and pull factors (Dann 1981). The present findings show that researchers need to differentiate between sexual orientation-based motivations and trans-based motivations.

In addition, in contrast to the allegedly well-off gay tourism segment, the economic power of trans tourism appears to be a myth. In multiple societies, many trans people have access to limited work opportunities, and these individuals are under- or unemployed due to social stigma, making them one of the poorest population segments (Molina et al. 2015; Queiroz Pereira and Costa Gomes 2017; Rodríguez-Madera et al. 2017). The present study confirmed that many trans people's financial situation is precarious, frequently involving insufficient income to participate actively in tourism. Although individuals within LGBT communities share many common experiences, the differences in obstacles faced by trans 
individuals due to homophobia and transphobia underline the need to understand these individuals' experiences independently (Zimman 2009).

In addition to financial barriers, trans people tend to experience specific constraints to their participation in tourism. The current research's results indicate that intrapersonal, interpersonal and structural constraints are experienced by trans people in tourism contexts, but intrapersonal barriers are the most salient. In trans tourism, the three types of constraints are often strongly associated with social stigma and its consequences. These include fear of being discriminated against, attacked or even murdered; family disapproval and no stable partner; and unsafe environments and gendered facilities, which are barriers associated with negative attitudes and prejudice towards gender dissidence.

These findings do not mean that trans individuals' constraints are all related to safety and transphobia, as trans people may also be subject to barriers based on age and financial and physical conditions. However, gender dissidence, particularly when overt, plays a significant role in defining these individuals' desire to engage - and their actual participation - in tourism. This finding concurs with Brumbaugh-Johnson and Hulls's (2018) assertion that 'transgender people must seriously consider personal safety risks when revealing their gender identity' (p. 24).

Shores et al. (2007) argue that constraints on leisure and tourism activities are not experienced equally by all social groups as these barriers may be more serious for people in non-dominant groups. This argument is empirically supported by the present study. Unlike other minority groups, trans people's constraints appear to be often strongly related to their own being, that is, to their identity. For some trans individuals, gender dissidence seems to be a more important constraint as compared to age, disability, time or financial condition, which frequently can be negotiated to allow participation in tourism (Jackson et al. 1993). This last finding is supported by the evidence provided by the current research that trans people who have free time and/or enough income to travel may worry the most about the fear for experiencing discrimination.

Gender expression is, by definition, always exposed to the public gaze, so trans individuals can feel constrained much of the time and become victims of transphobia at any point, making these individuals even more vulnerable in unfamiliar environments. The 
pervasive fear of being discriminated against, mistreated or even murdered due to their gender identity appears to be an important constraint experienced exclusively by many trans people. Some trans individuals avoid travel and unfamiliar environments at all costs because of their fear of discrimination and murder. This behaviour can be explained by how, unlike interpersonal and structural constraints, intrapersonal barriers can significantly reduce opportunities to participate in tourism and leisure activities (Gilbert and Hudson 2000, p. 911).

In trans tourism, perceived constraints are gendered. As with cisgender travellers, both trans women and men are subject to gender relations' restrictions. The present study's results reveal that, compared with men, many women are more vulnerable to social stigma, discrimination and violence - including sexual harassment - particularly in public spaces. Valentine (1989) argues that, due to gender relations and patriarchal systems, public spaces are controlled by men, and women feel unsafe to go out due to a fear of male violence. This fear contributes to women's inability to enjoy independence and freedom in tourism contexts - a constraint also reported by women in leisure activities (Arnold and Shinew 1998; Henderson and Bialeschki 1993).

However, after gender transition, trans men move themselves into a more privileged position. They tend to be less noticeable as trans people, and, as males, they position themselves socially so that they have more power, supremacy and control. This finding explains why trans men appear to be more likely to travel solo. In contrast, many trans women are victims not only of homophobia and transphobia but also of unbalanced gender relations.

Constraints on tourism for trans and cisgender women are not exactly the same. The latter can encounter sexism, misogyny and danger, although often less so than trans women. Cisgender women's barriers are gendered also in terms of gender roles. Domestic responsibilities such as children, family and household tasks are constraints on travel for many cisgender women (Gilligan 1982). However, the current research found that many trans women do not have children and a partner, so their family and domestic responsibilities are minimum and they do not constitute a significant constraint on travel.

\section{Conclusion}


This study sought to critically explore the intrapersonal, interpersonal and structural constraints that trans individuals experience in tourism. The results support the conclusion that many trans people's barriers are closely related to social stigma manifested at multiple levels. Intrapersonal barriers, which largely arise from a fear of discrimination, violence and death, are the most significant. In addition to sharing structural constraints with specific cisgender groups (e.g. a lack of money), some trans individuals feel greater anxiety and fear in public spaces such as gendered toilets, beaches and pools where their gender dissidence is more conspicuous and socially problematic. Public spaces, including tourism contexts, tend to make trans people feel more vulnerable to the cisgender and heteronormative public gaze and its negative consequences. According to Doan (2010), trans people experience the gendered division of space as a special kind of tyranny that has significant and painful consequences for many individuals.

From a gender perspective, the present findings include that trans people do not experience tourism constraints equally. Trans women tend to be vulnerable to both cisgenderism and transphobia and often, as females, traditional gender relations and patriarchal systems, subjecting them to inequalities in terms of safety conditions, access to opportunities and use of public space. In contrast, trans men's constraints can be reduced because they have moved to a social position that often includes masculine power and control of public spaces. Thus, this study's findings contribute to a more accurate understanding of how tourism constraints are perceived by trans people, thereby demonstrating the value of applying leisure and tourism constraints theory to gender dissidence research.

These findings have some implications for managers. The tourism industry can modify its service procedures to reduce trans individuals' fear for their safety and the potential for being discriminated against due to their gender identity. Tourism service providers' use of non-gendered language can also avoid these clients' feelings of being discriminated against or misgendered. The availability of ungendered facilities, including toilets, could also contribute to reducing intrapersonal constraints on trans travellers and thus reduce the impositions of structural social norms.

This study's limitations need to be mentioned. The research was exploratory in nature, and, because of its qualitative approach, the findings should not be regarded as equally 
applicable to other trans populations. Given that the sample included more trans women than trans men, the former's constraints might have been overly emphasised and trans men's voices insufficiently heard. Future research needs, therefore, to encompass larger samples and an equal number of trans women and men. The study investigated trans people's constraints, which are often surmountable, so further research is needed to examine in depth which, why and how negotiation strategies are adopted by trans individuals to make their participation in tourism more effective.

\section{Acknowledgements}

This research was supported by Universidad Autónoma del Estado de México (project $4866 / 2019 S F)$. The authors would like to express their gratitude to the women and men who participated in this study for their invaluable support.

\section{References}

Adler, A., S. J. Kless, and P. Adler. 1992. "Socialization to gender roles: Popularity among elementary school boys and girls." Sociology of Education 65(3), 169-187.

Alegre, J., S. Mateo, and L. Pou. 2010. “An analysis of households' appraisal of their budget constraints for potential participation in tourism." Tourism Management 31(1), $45-56$.

Arnold, M. L., and K. J. Shinew. 1998. "The role of gender, race, and income on park use constraints." Journal of Park and Recreation Administration 16(4), 39-56.

Blight, J. 2000. “Transgender inmates”. Trends and Issues in Crime and Criminal Justice, $168,1-6$.

Bockting, W. O., M. H. Miner, R. E. Swinburne Romine, A. Hamilton, and E. Coleman. 2013. "Stigma, mental health, and resilience in an online sample of the US transgender population." American Journal of Public Health 103(5), 943-951.

Božić, S., T. Jovanović, N. Tomić, and D. A. Vasiljević. 2017. “An analytical scale for domestic tourism motivation and constraints at multi-attraction destinations: The case study of Serbia's Lower and Middle Danube region." Tourism Management Perspectives, 23, 97-111. 
Bradford, J., S. L. Reisner, J. A. Honnold, and J. Xavier. 2013. “Experiences of transgenderrelated discrimination and implications for health: Results from the Virginia transgender health initiative study." American Journal of Public Health 103(10), 1820-1829.

Brennan, J., L. M. Kuhns, A. K. Johnson, M. Belzer, E. C. Wilson, and R. Garofalo. 2012. "Syndemic theory and HIV-related risk among young transgender women: The role of multiple, co-occurring health problems and social marginalization". American Journal of Public Health 102(9), 1751-1757.

Brito, A (coord.) 2019. “Violencia extrema. Los asesinatos de personas LGBTTT en México: los saldos del sexenio (2013-2018)." Letra S, Sida, Cultura y Vida Cotidiana A.C., México. $\quad$ Retrieved from: http://www.letraese.org.mx/wpcontent/uploads/2019/05/Informe-cr\%C3\%ADmenes-2018-v2.pdf, accessed 03 March 2020.

Brumbaugh-Johnson, S. M., and K. E. Hull. 2019. “Coming out as transgender: navigating the social implications of a transgender identity." Journal of Homosexuality 66(8), 1148-1177.

Budge, S. L., J. L. Adelson, and K. A. S. Howard. 2013. "Anxiety and sepression in transgender individuals: The roles of transition status, loss, social support, and coping." Journal of Consulting and Clinical Psychology 81(3), 545-557.

Chang, T. K., and Y. B. Chung. 2015. "Transgender microaggressions: complexity of the heterogeneity of transgender identities". Journal of LGBT Issues in Counseling $9(3), 217-234$.

Conapred, and CNDH. 2019. "Encuesta sobre discriminación por motivos de orientación sexual e identidad de género 2018". https://www.conapred.org.mx/userfiles/files/Presentacioon_ENDOSIG_16_05_2 019.pdf. accessed 03 March 2020

Crawford, D. W., G. Godbey. 1987. "Reconceptualizing barriers to family leisure.” Leisure Sciences 9(2), 119-127. 
Dann, G. M. S. 1981. “Tourist motivation an appraisal.” Annals of Tourism Research 8(2), 187-219.

Doan, P. L. 2010. "The tyranny of gendered spaces - reflections from beyond the gender dichotomy." Gender, Place \& Culture, 17(5), 635-654

Dutton, L., K. Koenig, and K. Fennie. 2008. "Gynecologic care of the female-to-male transgender man." Journal of Midwifery and Women's Health 53(4), 331-337.

Editorial. 2016. "Structural constraints and individual choices." Studies of Transition States and Societies 8(3), n/p.

Fendt, L. S., and E. Wilson. 2012. “"I just push through the barriers because I live for surfing": How women negotiate their constraints to surf tourism." Annals of Leisure Research 15(1), 4-18.

Fleischer, A., and A. Pizam. 2002. "Tourism constraints among Israeli seniors." Annals of Tourism Research 29(1), 106-123.

Fundación Huésped. n/d. "Ley de identidad de género y acceso al cuidado de la salud de las personas trans en Argentina". Retrieved from: https://www.huesped.org.ar/wp-content/uploads/2014/05/OSI-informeFINAL.pdf, February 28, 2020.

Gao, J., and D. L. Kerstetter. 2016. “Using an intersectionality perspective to uncover older Chinese female's perceived travel constraints and negotiation strategies." Tourism Management 57, 128-138.

Gilbert, D., and S. Hudson. 2000. "Tourism demand constraints: A skiing participation." Annals of Tourism Research 27(4), 906-925.

Gilligan, C. 1982. In a different voice: Psychology and theory and women's development. Cambridge: Harvard University Press.

Godbey, G., D: W. Crawford, and X. S. Shen. 2010. "Assessing hierarchical leisure constraints theory after two decades." Journal of Leisure Research 42(1), 111-134.

Grant, J. M., L .A. Mottet, J. Tanis, with J. Harrison, J. L. Herman, and M. Keisling. 2011. Injustice at every turn. A report of the National Transgender Discrimination 
Survey.

Retrieved

from

https://www.transequality.org/sites/default/files/docs/resources/NTDS_Repor t.pdf

Guaracino, J., and E. Salvato. 2017. Handbook of LGBT tourism and hospitality: A guide for business practice. Harrington Park Press.

Hatzenbuehler, M. L., K. A. McLaughlin, K. M. Keyes, and D. S. Hasin. 2010. "The impact of institutional discrimination on psychiatric disorders in lesbian, gay, and bisexual populations: a prospective study." Am J Public Health 100(3):452-459.

Henderson, K. A., and M. D. Bialeschki. 1993. "Negotiating constraints to women's physical recreation." Loisir et Societé 16(2), 389-411.

Hinch, T. D., and E. L. Jackson. 2000. "Leisure constraints research: Its value as a framework for understanding tourism seasonability." Current Issues in Tourism 3(2), 87-106.

Howe, C., S. Zaraysky, and L. Lorentzen. 2008. "Transgender sex workers and sexual transmigration between Guadalajara and San Francisco." Latin American Perspectives 35(1), 31-50.

Huber, D., S. Milne, and K. F. Hyde. 2018. "Constraints and facilitators for senior tourism." Tourism Management Perspectives 27, 55-67.

Hudson, S., and D. Gilbert. 2000. "Tourism constraints: The neglected dimension in consumer behaviour research." Journal of Travel and Tourism Marketing 8(4), 6978.

Hughes, H. 1997. "Holidays and homosexual identity." Tourism Management 18(1), 3-7.

Jackson, E. L., D. W. Crawford, and G. Godbey. 1993. "Negotiation of leisure constraints.” Leisure Sciences 15(1), 1-11.

Kattiyapornpong, U., and K. E. Miller. 2009. "Socio-demographic constraints to travel behavior." International Journal of Culture, Tourism and Hospitality Research 3(1), 81-94. 
Killion, L., and R. Fisher. 2018. "Ontology, epistemology: Paradigms and parameters for qualitative approaches to tourism research." In W. Hillman, and K. Radel (Eds.) Qualitative methods in tourism research. Theory and practice (pp. 1-28). Briston: Channel View Publications.

Lee, B. K., S. Agarwal, \& H. J. Kim. 2012. "Influences of travel constraints on the people with disabilities' intention to travel: An application of Seligman's helplessness theory." Tourism Management 33(3), 569-579.

Lennon, E., and B. J. Mistler. 2014. “Cisgenderism”. Transgender Studies Quarterly 1(1-2), 63-64.

Link, B. G., and J. C. Phelan. 2001. "Conceptualizing stigma”. Annual Review of Sociology $27,363-385$.

Maguen, S., J. C. Shipherd, H. N. Harris, and L. P. Welch. 2007. "Prevalence and predictors of disclosure of transgender identity." International Journal of Sexual Health 19(1), 3-13.

Marshall, Z., V. Welch, A. Minichiello, M. Swab, F. Brunger, and C. Kaposy. 2019. "Documenting research with transgender, nonbinary, and other gender diverse (trans) Individuals and communities: Introducing the global trans research evidence map." Transgender Health 4(1), 68-80.

Martín-Palomino, E. T., and A. González Ramos. 2014. “"Laissez faire, laissez passer”: The sexual commodification of women's and girls' bodies from a gender perspective." Dilemata 16, 85-100.

Meseguer, D. 2017. "A los hombres trans nos felicitan, a las mujeres trans las matan". PlayGround, 06 July. Retrieved from: https://playgroundmag.net/do/Halagotrans-felicitados-mujeres-asesinadas-transfobia-lgbti_22583688.html, accessed 06 March 2020.

Molina, N., O. Guzmán, and A. Martínez-Guzmán. 2015. “Identidades, transgénero y transfobia en el contexto mexicano: Una aproximación narrativa." Quaderns de Psicología 17(3), 71-82. 
Monterrubio, C., S. L. Rodríguez Madera, and J. Pérez. 2020. "Trans women in tourism: Motivations, constrains and experiences." Journal of Hospitality and Tourism Management 43, 169-178.

Monterrubio, J. C. 2009. “Identity and sex: Concurrent aspects of gay tourism.” Tourismos. An International Multidisciplinary Journal of Tourism 4(2), 155-167.

Notimex. 2019, February 4. "En México hay entre 360 mil y 600 mil personas trans, según estudio." Noticieros Televisa. $\quad$ Retrieved from https://noticieros.televisa.com/ultimas-noticias/mexico-personas-transgenerosexualidad-poblacion/

Nyaupane, G. P., and K. L. Andereck. 2008. “Understanding travel constraints: Application and extension of a leisure constraints model." Journal of Travel Research 46(4), 433-439.

Nyaupane, G. P., D. B. Morais, and A. R. Graefe. 2004. "Nature tourism constraints: A crossactivity comparison." Annals of Tourism Research 31(3), 540-555.

Olson, E. D., and K. Reddy-Best. 2019. “"Pre-topsurgery, the body scanning machine would most likely error:" Transgender and gender nonconforming travel and tourism experiences." Tourism Management 70, 250-261.

Padilla, M. B., S. Rodríguez-Madera, N. Varas-Díaz, and A. Ramos-Pibernus. 2016. "Transmigrations: border-crossing and the politics of body modification among Puerto Rican transgender women." International Journal of Sexual Health 28(4), 261-277.

Pennington-Gray, L. A., and D. L. Kerstetter. 2002. "Testing a constraints model within the context of nature-based tourism." Journal of Travel Research 40, 416-423.

Phelan, J. C., B. G. Link, and J. F. Dovidio. 2008. “Stigma and prejudice: one animal or two?" Soc Sci Med. 67(3), 358-67.

Pritchard, A., N. J. Morgan, D. Sedgley, E. Khan, and A. Jenkins. 2000. "Sexuality and holiday choices: Conversations with gay and lesbian tourists." Leisure Studies 19(4), 267282. 
Queiroz Pereira, F., and J. M. Costa Gomes. 2017. "Poverty and gender: The marginalization of transvestites and transsexuals by the law." Revista Direitos Fundamentais \& Democracia 22(2), 210-224.

Rands, K. E. 2009. “Considering transgender people in education. A gender-complex approach." Journal of Teacher Education, 60(4), 419-431.

Reisner, S. L., J. M. White, J. B. Bradford, and M. J. Mimiaga. 2014. "Transgender health disparities: Comparing full cohort and nested matched-pair study designs in a community health center." LGBT Health 1(3), 177-184.

Rodríguez Madera, S. L., N. V. Díaz, M. Padilla, A. R. Pibernus, T. B. Neilands, E. R. Segarra, C. M. Pérez Velázquez, and W. Bockting. 2019. “"Just like any other patient”: Transgender stigma among physicians in Puerto Rico." Journal of Health Care for the Poor and Underserved 30(4), 1518-1542.

Rodríguez Madera, S., A. Ramos Pibernus, M. Padilla, and N. Varas Díaz. 2015. “Radiografía de las comunidades trans en Puerto Rico: Visibilizando femineidades y masculinidades alternas”. In M. Vázquez-Rivera, A. Martínez Taboas, M. FranciaMartínez, and J. Toro-Alfonso (Eds.) LGBT 101: Una mirada introductoria al colectivo (pp. 290-314). San Juan, PR: Publicaciones Puertorriqueñas.

Rodríguez-Madera, S. L., M. Padilla, N. Varas-Díaz, T. Neilands, A. C. Vasques Guzzi, E. J. Florenciani, and A. Ramos-Pibernus. 2017. "Experiences of violence among transgender women in Puerto Rico: An underestimated problem." Journal of Homosexuality 64(2), 209-217.

Sears, B., and C. Mallory. 2011. “Documented evidence of employment discrimination and its effects on LGBT people". In The Williams Institute. Retrieved from http://williamsinstitute.law.ucla.edu/wp-content/uploads/Sears-MalloryDiscrimination-July-20111.pdf

Shores, K. A., D. Scott, and M. F. Floyd. 2007. “Constraints to outdoor recreation: A multiple hierarchy stratification perspective." Leisure Sciences 29(3), 227-246.

Smith, R. W. 1987. "Leisure of disabled tourists. Barriers to participation." Annals of Tourism Research, 14(3), 376-389. 
Snepenger, D., J. King, E. Marshal, and M. Uysal. 2006. "Modeling Iso-Ahola's motivation theory in the tourism context." Journal of Travel Research 45(2), 140-149.

Socías, M. E., B. D. L. Marshall, I. Arístegui, M. Romero, P. Cahn, T. Kerr, and O. Sued. 2014. "Factors associated with healthcare avoidance among transgender women in Argentina." International Journal for Equity in Health 13(1), 1-8.

Son, J. S., D. L. Kerstetter, and A. J. Mowen. 2008. "Do age and gender matter in the constraint negotiation of physically active leisure?" Journal of Leisure Research 40(2), 267-289.

Stotzer, R. L. 2009. "Violence against transgender people: A review of United States data." Aggression and Violent Behavior 14, 170-179.

TGEU. 2019. TMM update trans day of remembrance 2019. Retrieved from https://transrespect.org/en/tmm-update-trans-day-of-remembrance-2019/

Valentine, G. 1989. “The geography of women's fear”. Area 21, 385-390.

Vera Morales, A. 2019. La situación de acceso a derechos de las personas trans en México: $\begin{array}{llll}\text { Problemáticas } & \mathrm{y} & \text { propuestas. Retrieved }\end{array}$ https://almascautivasorg.files.wordpress.com/2019/02/la-situacic3b3n-deacceso-a-derechos-de-las-personas-trans-en-mc3a9xico-investigacic3b3ncompleta.pdf

Vincent, B. W. 2018. "Studying trans: recommendations for ethical recruitment and collaboration with transgender participants in academic research." Psychology \& Sexuality, 9(2), 102-116.

Waitt, G., and K. Markwell. 2006. Gay tourism. Culture and context. The Haworth Hospitality Press.

Weeden, C., J. A. Lester, and N. Jarvis. 2016. “Lesbians and gay men’s vacation motivations, perceptions, and constraints: A study of cruise vacation choice." Journal of Homosexuality 63(8), 1068-1085. 
White Hughto, J. M., S. L. Reisner, and J. E. Pachankis. 2015. "Transgender stigma and health: A critical review of stigma determinants, mechanisms, and interventions." Social Science \& Medicine, 147, 222-231.

Wilson, E., and D. E. Little. 2005. “A 'relative escape'? The impact of constraints on women who travel solo." Tourism Review International 9(2), 155-175.

Wirtz, A. L., T. C. Poteat, M. Malik, and N. Glass. 2020. “Gender-based violence against transgender people in the United States: A call for research and programming." Trauma, Violence, and Abuse 21, 227-241.

Zimman, L. 2009. “'The other kind of coming out': Transgender people and the coming out narrative genre." Gender and Language 3(1), 53-80. 